\title{
VIABILIDADE ECONÔMICA DE MANEJOS NUTRICIONAIS NA CULTURA DE BANANA ${ }^{1}$
}

\author{
Fernanda de Paiva Badiz Furlaneto ${ }^{2}$, Adriana Novais Martins ${ }^{3}$, Maura Seiko Tsutsui Esperancini ${ }^{4}$
}

\begin{abstract}
ECONOMIC VIABILITY OF NUTRIENT

MANAGEMENT PRACTICES FOR BANANA CROP

Proper fertilizing management, in order to optimize fruit quality and yield, is a relevant stage on the production process to the rural entrepreneur profitability. So, the aim of this study was to analyze the economic feasibility of five nutrient management practices for banana crop, Cavendish cultivars, in the Médio Paranapanema region, São Paulo State, Brazil, in 2009/2010. The effective operational cost (EOC) and total operational cost (TOC) structures and three profitability indicators were used. Significant differences were observed among the management systems, and the system that resulted in major economic advantage to the producer provided an average profit rate $25.6 \%$ higher than other treatments, with total net revenue about $29.5 \%$ higher than other management types. The unitary cost was lower for the most profitable nutrient management practice, although the yield was $9.5 \%$ lower than the management system that presented the highest yield levels.
\end{abstract}

KEY-WORDS: Musa spp.; banana crop; fertilization; production cost; profitability.

\section{INTRODUÇÃO}

Dentre as culturas agrícolas, a bananicultura é uma das mais importantes nas regiões tropicais e subtropicais do mundo, estendendo-se por uma área estimada em 4,8 milhões de hectares, com produtividade média de 19 toneladas ha ${ }^{-1}$ ano $^{-1}$ e produção total de 95,6 milhões de toneladas, gerando receitas de, aproximadamente, 8,5 bilhões de dólares ao ano e beneficiando muitos países em desenvolvimento (Agrianual 2010).

A banana tem um excelente valor nutricional, sendo um dos alimentos mais facilmente digeríveis.

\section{RESUMO}

O manejo adequado da adubação, visando à otimização da produtividade e qualidade dos frutos, é uma etapa representativa do processo produtivo para rentabilidade do empreendedor rural. Neste contexto, objetivou-se analisar a viabilidade econômica de cinco tipos de manejo nutricional de bananeiras de cultivares do subgrupo Cavendish, na região do Médio Paranapanema (SP), em 2009/2010. Foram utilizadas estruturas do custo operacional efetivo (COE) e custo operacional total (COT) e três indicadores de rentabilidade. Diferenças significativas foram observadas entre os manejos, sendo que o sistema de manejo que resultou em maior vantagem econômica para o produtor proporcionou índice médio de lucratividade $25,6 \%$ superior aos demais tratamentos, além de a receita líquida total ser, em média, 29,5\% superior aos outros tipos de manejo. $\mathrm{O}$ custo por unidade produzida foi inferior no manejo nutricional mais lucrativo, apesar de a produtividade ter sido $9,5 \%$ inferior ao manejo que apresentou os maiores índices de produtividade.

PALAVRAS-CHAVE: Musa spp.; bananicultura; adubação; custo de produção; rentabilidade.

Por estas características e pelo seu potencial produtivo, que pode alcançar até 100 toneladas $\mathrm{ha}^{-1} \mathrm{ano}^{-1}$, a cultura da banana representa papel estratégico na segurança alimentar mundial (Silva Neto \& Guimarães 2011).

No Brasil, apesar das condições favoráveis à produção da fruta, a produtividade tem sido baixa, em função de problemas de suprimento nutricional e hídrico (Fernandes et al. 2008, Santos 2009). No País, os produtores rurais buscam atender apenas à necessidade nutricional da planta-mãe, sendo insuficiente o suprimento de nutrientes, no decorrer do ciclo de produção (Soares et al. 2008).

1. Trabalho recebido em ago./2010 e aceito para publicação em maio/2011 (nº registro: PAT 10813/ DOI: 10.5216/pat.v41i2.10813).

2. Agência Paulista de Tecnologia dos Agronegócios (APTA), Pólo Centro-Oeste Paulista, Unidade de Pesquisa e

Desenvolvimento, Marília, SP, Brasil.E-mail: fernandafurlaneto@apta.sp.gov.br.

3. Agência Paulista de Tecnologia dos Agronegócios (APTA), Pólo Médio Paranapanema, Assis, SP, Brasil.

E-mail: adrianamartins@apta.sp.gov.br.

4. Universidade Estadual Paulista, Campus Botucatu, Departamento de Gestão e Tecnologia Agroindustrial, Botucatu, SP, Brasil.

E-mail: maura@fca.unesp.br. 
Por ser uma planta de desenvolvimento rápido, a bananeira exige elevadas concentrações de alguns elementos, para suprir sua demanda nutricional (Nava \& Illarreal 2000). Os principais nutrientes requeridos pela planta são o nitrogênio e o potássio, que podem ser fornecidos por meio da adubação foliar e via solo. O nitrogênio é importante para o crescimento vegetativo, aumento do número de pencas e emissão e crescimento de rebentos. O potássio atua na translocação de fotoassimilados, balanço hídrico, produção, resistência e qualidade dos frutos (Borges \& Oliveira 2000).

A sustentabilidade dos cultivos de bananeira tem sido associada às condições de fertilidade do solo, por diversos autores (Teixeira et al. 2007, Santos 2008, Moreira \& Fageria 2009). No entanto, muitos fatores inerentes ao manejo nutricional podem causar interferências nos processos fisiológicos e estão ligados à disponibilidade, absorção e redistribuição dos nutrientes na planta.

Além das questões relacionadas à produtividade e qualidade dos frutos, o manejo da adubação é uma etapa do processo produtivo de grande relevância para a rentabilidade do produtor, pois representa um dos custos mais elevados da produção agrícola. Portanto, a identificação de sistemas mais eficientes de adubação, sob o ponto de vista econômico, é primordial para a tomada de decisão do bananicultor (Furlaneto et al. 2005, Kogler et al. 2006).

Neste sentido, este trabalho teve como objetivo analisar a viabilidade econômica de cinco tipos de manejo nutricional de bananeiras de cultivares do subgrupo Cavendish, no Médio Paranapanema, região com destaque, em produtividade, no Estado de São Paulo.

\section{MATERIAL E MÉTODOS}

Fonte de dados, caracterização da região e dos sistemas de produção

As informações que subsidiaram a pesquisa foram coletadas em propriedades rurais com sistemas de produção representativos da região do Médio Paranapanema, Estado de São Paulo, nos municípios de Palmital, Cândido Mota, Ibirarema, Iepê e Tarumã, de janeiro de 2009 a janeiro de 2010. As propriedades selecionadas apresentam área média com bananicultura de 5 hectares. Os produtores possuem nível médio de tecnificação com, pelo menos, um empregado contratado em carteira e utilizam as técnicas agronômicas preconizadas para a cultura, como adubação, controle fitossanitário e tratos culturais. As propriedades foram distribuídas de acordo com a representatividade de cada município.

O Médio Paranapanema situa-se a sudoeste do Estado de São Paulo e caracteriza-se pela predominância de latossolos de textura média e álicos. O clima é moderadamente úmido, sem estação seca definida, com precipitação do mês mais seco superior a $30 \mathrm{~mm}$, temperatura média do mês mais frio inferior a $18^{\circ} \mathrm{C}$, mas acima de $-3^{\circ} \mathrm{C}$, e temperatura média do mês mais quente superior a $22^{\circ} \mathrm{C}$. A precipitação anual atinge valores médios de $1.260 \mathrm{~mm}$ (Prado et al. 2003).

Os coeficientes técnicos foram obtidos por meio da aplicação de questionários, junto aos bananicultores, em 30 propriedades com sistema de plantio convencional de sequeiro, em lavouras com diferentes estádios fenológicos. Os preços médios dos itens que compuseram a planilha de custo, utilizados no trabalho, foram obtidos nos municípios de Assis e Pedrinhas Paulista, em decorrência de estas cidades possuírem cooperativas de produtos agrícolas que atendem à região do Médio Paranapanema. $\mathrm{O}$ preço médio de venda da fruta ( $\mathrm{R} \$ 8,60$ a caixa de $22 \mathrm{~kg}$ ) foi determinado em função da média do preço anual recebido pelos agricultores regionais. A cotação do dólar correspondeu a $\mathrm{R} \$ 1,84$.

A tecnologia predominante constitui-se das operações de aração, gradagem, calagem, abertura de covas, transporte e distribuição de mudas, adubação, plantio e replantio. As mudas utilizadas foram de rizoma e o período anual médio de colheita foi de 10 meses. O espaçamento médio de plantio foi de 2,0 m x 2,5 m, resultando em 2.000 famílias hä ${ }^{-1}$. Foram analisados os cinco primeiros anos da cultura, sendo o primeiro ano (ano 1) denominado "ano de formação da lavoura" e os anos 2 a 5 como "fase de produção", e cinco tipos de manejo nutricional (Tabela 1). A vida útil da cultura, na região, é de, aproximadamente, 12 anos.

\section{Determinação de custos e rentabilidade}

A metodologia para determinação dos custos foi baseada em Matsunaga et al. (1976), como se segue: 1) custo operacional efetivo (COE): constitui o somatório dos custos com a utilização de mão de obra, máquinas, equipamentos e insumos; 2) custo operacional total (COT): resulta do somatório do 
Tabela 1. Descrição dos cinco tipos de manejo nutricional utilizados na produção de bananeiras do subgrupo Cavendish (Região do Médio Paranapanema, SP, 2009/2010).

\begin{tabular}{|c|c|c|c|c|c|c|}
\hline \multirow{3}{*}{ Especificações } & \multicolumn{6}{|c|}{ Manejo nutricional } \\
\hline & \multirow[b]{2}{*}{ Unidade } & Formação & $2^{\circ}$ ano & $3^{\circ}$ ano & $4^{\circ}$ ano & $5^{\circ}$ ano \\
\hline & & \multicolumn{5}{|c|}{ Quantidade } \\
\hline \multicolumn{7}{|l|}{ Manejo Nutricional 1 (MN1) } \\
\hline Calcário dolomítico & $\mathrm{t}$ & 1,5 & & & 1,0 & \\
\hline Super simples & $\mathrm{t}$ & 0,6 & & & & \\
\hline Sulfato de amônia & $\mathrm{t}$ & 0,3 & & & & \\
\hline Cloreto de potássio & $\mathrm{t}$ & 0,2 & 0,5 & 0,5 & 0,5 & 0,5 \\
\hline Adubo 20.50 .20 & $\mathrm{t}$ & & 1,1 & 1,1 & 1,1 & 1,1 \\
\hline Ácido bórico & $\mathrm{kg}$ & & & 10,0 & 10,0 & 10,0 \\
\hline Sulfato de zinco & $\mathrm{kg}$ & & & 40,0 & 40,0 & 40,0 \\
\hline Produtividade & $\mathrm{t}$ & & 30,0 & 35,0 & 40,0 & 40,0 \\
\hline \multicolumn{7}{|l|}{ Manejo Nutricional 2 (MN2) } \\
\hline Calcário dolomítico & $\mathrm{t}$ & 1,5 & & & 1,5 & \\
\hline Super simples & $\mathrm{t}$ & 0,6 & & & & \\
\hline Sulfato de amônia & $\mathrm{t}$ & 0,5 & 1,5 & 1,5 & 1,5 & 1,5 \\
\hline Cloreto de potássio & $\mathrm{t}$ & 0,3 & 1,0 & 1,0 & 1,0 & 1,0 \\
\hline Adubo 20.50 .20 & $\mathrm{t}$ & & & & & \\
\hline Ácido bórico & $\mathrm{kg}$ & & 10,0 & 10,0 & 10,0 & 10,0 \\
\hline Sulfato de zinco & $\mathrm{kg}$ & & 40,0 & 40,0 & 40,0 & 40,0 \\
\hline Produtividade & $\mathrm{t}$ & & 35,0 & 40,0 & 45,0 & 50,0 \\
\hline \multicolumn{7}{|l|}{ Manejo Nutricional 3 (MN3) } \\
\hline Calcário dolomítico & $\mathrm{t}$ & 1,5 & & & & \\
\hline Termofosfato magnesiano $\left(17 \% \mathrm{P}_{2} \mathrm{O}_{5}\right)$ & $\mathrm{t}$ & 0,6 & & & & \\
\hline Esterco de galinha & $\mathrm{t}$ & 2,0 & & & & \\
\hline Super simples & $\mathrm{t}$ & & & & & \\
\hline Sulfato de amônia & $\mathrm{t}$ & 0,3 & & & & \\
\hline Cloreto de potássio & $\mathrm{t}$ & 0,3 & & & & \\
\hline Adubo 14.07.28 & $\mathrm{t}$ & & 2,0 & 2,0 & 2,0 & 2,0 \\
\hline Adubo 20.50 .20 & $\mathrm{t}$ & & & & & \\
\hline Ácido bórico & $\mathrm{kg}$ & & 10,0 & 10,0 & 10,0 & 10,0 \\
\hline Sulfato de zinco & $\mathrm{kg}$ & & 40,0 & 40,0 & 40,0 & 40,0 \\
\hline Produtividade & $\mathrm{t}$ & & 40,0 & 45,0 & 50,0 & 55,0 \\
\hline \multicolumn{7}{|l|}{ Manejo Nutricional 4 (MN4) } \\
\hline Calcário dolomítico & $\mathrm{t}$ & 1,5 & & & & \\
\hline Termofosfato magnesiano $\left(17 \% \mathrm{P}_{2} \mathrm{O}_{5}\right)$ & $\mathrm{t}$ & 0,6 & & & & \\
\hline Esterco de galinha & $\mathrm{t}$ & 2,0 & & & & \\
\hline Super simples & $\mathrm{t}$ & & & & & \\
\hline Sulfato de amônia & $\mathrm{t}$ & 0,3 & & & & \\
\hline Cloreto de potássio & $\mathrm{t}$ & 0,3 & 1,0 & 1,0 & & 1,0 \\
\hline Fertilizante nitrogenado de liberação gradual (26.00.00) & $\mathrm{t}$ & & 1,0 & 1,0 & 1,0 & 1,0 \\
\hline Adubo 14.07 .28 & $\mathrm{t}$ & & & & 1,0 & \\
\hline Adubo 20.50 .20 & $\mathrm{t}$ & & & & & \\
\hline Ácido bórico & $\mathrm{kg}$ & & 10,0 & 10,0 & 10,0 & 10,0 \\
\hline Sulfato de zinco & $\mathrm{kg}$ & & 40,0 & 40,0 & 40,0 & 40,0 \\
\hline Produtividade & $\mathrm{t}$ & & 40,0 & 45,0 & 50,0 & 55,0 \\
\hline \multicolumn{7}{|l|}{ Manejo Nutricional 5 (MN5) } \\
\hline Calcário dolomítico & $\mathrm{t}$ & 1,5 & & & & \\
\hline Termofosfato magnesiano $\left(17 \% \mathrm{P}_{2} \mathrm{O}_{5}\right)$ & $\mathrm{t}$ & 0,4 & & & & \\
\hline Esterco de galinha & $\mathrm{t}$ & 2,0 & & & & \\
\hline Super simples & $\mathrm{t}$ & & & & & \\
\hline Sulfato de amônia & $\mathrm{t}$ & 0,3 & & & & \\
\hline Cloreto de potássio & $\mathrm{t}$ & 0,3 & & & & \\
\hline 10.10 .30 & $\mathrm{t}$ & & 1,5 & 1,5 & 1,5 & 1,5 \\
\hline $10.00 .18+13 \% \mathrm{Ca}+0,21 \% \mathrm{~B}$ & $\mathrm{t}$ & & 0,5 & 0,5 & 0,5 & 0,5 \\
\hline $15.09 .20+1,2 \% \mathrm{Mg}+4 \% \mathrm{~S}$ & $\mathrm{t}$ & & 0,5 & 0,5 & 0,5 & 0,5 \\
\hline $09.00 .24+11,4 \% \mathrm{Ca}+0,18 \% \mathrm{~B}$ & $\mathrm{t}$ & & 0,5 & 0,5 & 0,5 & 0,5 \\
\hline Produtividade & & & 45,0 & 50,0 & 55,0 & 60,0 \\
\hline
\end{tabular}

Fonte: Dados da pesquisa (2010). 
custo operacional efetivo (COE) e dos custos indiretos monetários ou não monetários, tais como: a) depreciação de máquinas, equipamentos e benfeitorias; b) encargos diretos: $33 \%$ sobre a mão de obra; c) contribuição de seguridade social (CESSR): $2,3 \%$ sobre a receita bruta; $d$ ) encargos financeiros: $8,75 \%$ a.a. sobre $50 \%$ do COE; e) despesas com assistência técnica: $2 \%$ sobre o $\mathrm{COE} ; 3$ ) custo operacional acumulado (COT acumulado): representa o somatório dos custos operacionais totais, no decorrer dos anos. O custo de cada manejo nutricional foi somado ao valor obtido no custo total de produção e rateado pela produtividade anual de cada sistema produtivo.

O custo operacional efetivo (COE) foi dividido em três itens: a) operações mecanizadas, que incluem o custo de máquinas e implementos com preparo da área, implantação da lavoura, tratos culturais e colheita; b) operações manuais, representadas pelo custo do trabalho do homem, referente ao preparo da área, implantação da lavoura, tratos culturais e colheita; c) insumos, divididos em dois subitens: 1) corretivos e fertilizantes e 2) demais produtos (mudas, defensivos e sacos plásticos). $\mathrm{O}$ custo operacional total (COT) foi estimado somando-se o item "outros" (depreciação de máquinas e implementos, encargos sociais diretos, assistência técnica, encargos financeiros e CESSR) ao valor do COE. O custo do plantio e formação da lavoura foi dividido nos anos 2 a 5 , para fins de estimativa do custo por unidade de quilo produzido e receita líquida. Os indicadores da análise de viabilidade econômica foram calculados de acordo com Martin et al. (1998), como se segue: a) Receita bruta $=$ Produtividade $\mathrm{x}$ Preço médio de venda; b) Receita líquida = Receita bruta - COT; c) Índice de lucratividade = Lucro operacional/ Receita bruta.

\section{RESULTADOS E DISCUSSÃO}

Nos cinco sistemas de produção, o custo das operações mecanizadas e manuais do plantio e formação da lavoura foram semelhantes, pois utilizou-se a técnica padrão recomendada para a cultura. A partir do $2^{\circ}$ ano, obteve-se um custo operacional para cada manejo, visto que a adubação e a produtividade foram diferenciadas entre os sistemas produtivos.

$\mathrm{O}$ COE do Ano 1 foi inferior no MN1 ( R \$ 7.078,5 ha-1) e MN2 (R\$ 7.370,8 ha-1), respectivamente, devido ao uso somente de fertilizantes químicos. Nos manejos 3, 4 e 5, utilizaram-se adubos químico e orgânico.

Kogler et al. (2006) descreveu que o custo de implantação do pomar de banana, cultivar Willians, em Bom Jesus da Lapa, BA, para uma produtividade de $70 \mathrm{t} \mathrm{ha}^{-1}$, foi de $\mathrm{R} \$ 6.194,5 \mathrm{ha}^{-1}$. Furlaneto et al. (2007) verificaram que o investimento de plantio e formação de banana, cultivares do subgrupo Cavendish, na região do Médio Paranapanema, SP, no ano 2007 , correspondeu a $\mathrm{R} \$ 8.554,7 \mathrm{ha}^{-1}$, valor próximo ao estimado neste trabalho.

Nos anos 2 a 5, os tratamentos menos onerosos corresponderam ao MN1 e MN3, devido ao tipo de fertilizante empregado em cada manejo. Ressalta-se que, no MN3, MN4 e MN5, foram usados dois ou mais adubos formulados. Já no MN2, contabilizaram-se doses superiores de sulfato de amônia e cloreto de potássio, em relação ao MN1 e MN3.

O custo total acumulado do MN5 (mais oneroso) foi 34,5\% superior ao MN1 (mais econômico), porém, a média do custo por unidade produzida foi menor no MN3 (R\$ 0,27) e MN4 (R\$ 0,28), respectivamente. O MN1 apresentou maior custo ( R\$ 0,32), em decorrência da baixa produção por hectare (Tabelas 2, 3 e 4).

No Vale do Ribeira, Estado de São Paulo, em 2009, o custo total acumulado para o cultivo de banana nanica, com produtividade média de $39 \mathrm{tha}^{-1}$, foi de R \$ 41.588,0 (Agrianual 2010). Porém, Furlaneto et al. (2007) verificaram que, para a produção de banana, subgrupo Cavendish, na região do Médio Paranapanema, com produtividade média de $46,5 \mathrm{t} \mathrm{ha}^{-1}$, em 2007, este custo foi equivalente a $\mathrm{R} \$ 36.343,5$.

A produtividade média do $\mathrm{MN} 1$ correspondeu a 36 t ha $^{-1}$ ano $^{-1}$; a do MN2 a $41 \mathrm{t} \mathrm{ha}^{-1}$ ano $^{-1}$; do MN3 a $47 \mathrm{t} \mathrm{ha}^{-1} \mathrm{ano}^{-1}$; do MN4 a $47 \mathrm{t} \mathrm{ha}^{-1}$ ano $^{-1}$; e do MN5 a $52 \mathrm{t} \mathrm{ha}^{-1}$ ano $^{-1}$. Já Leite (2001) descreveu que, na região sudeste da Bahia, o rendimento esperado por cultivar é de 13-15 t ha-1 ano $^{-1}$, para 'Prata'; 15-20 t ha ${ }^{-1}$ ano $^{-1}$, para 'Pacovan'; 15-20 t ha ${ }^{-1}$ ano $^{-1}$, para 'Prata-anã'; 10-12 t ha-1 ano $^{-1}$, para 'Maçã'; 25-30 t ha-1 ano $^{-1}$, para 'Nanicão'; e 15-20 t ha ${ }^{-1}$ ano $^{-1}$, para a 'Terra'. Em Rondônia, o rendimento médio da banana equivale a $8 \mathrm{t} \mathrm{ha}^{-1} \mathrm{ano}^{-1}$ (Oliveira \& Rocha 2007). No Estado de São Paulo, na região do Médio Paranapanema, em 2008, a produção média de banana correspondeu a 60,0 t ha-1 ano $^{-1}$ (Martins 2010).

Os indicadores de rentabilidade apontaram que a maior receita líquida foi obtida no MN3, apesar de a receita bruta ter sido inferior ao MN5 (Tabela 5). 
Tabela 2. Estimativa do custo de produção de bananeiras do subgrupo Cavendish, de acordo com o tipo de manejo nutricional (MN1 e MN2), em reais por hectare (Região do Médio Paranapanema, SP, 2009/2010).

\begin{tabular}{|c|c|c|c|c|c|}
\hline \multirow{2}{*}{ Especificações } & \multicolumn{5}{|c|}{ Manejo Nutricional 1 (MN1) } \\
\hline & Formação & $2^{\circ}$ ano & $3^{\circ}$ ano & $4^{\circ}$ ano & $5^{\circ}$ ano \\
\hline \multicolumn{6}{|l|}{ A. Operações mecanizadas } \\
\hline Preparo da área & 325,51 & - & - & - & - \\
\hline Implantação & 133,06 & - & - & - & - \\
\hline Tratos culturais & 195,15 & 436,85 & 442,63 & 442,63 & 442,63 \\
\hline Colheita & - & 325,42 & 364,46 & 416,53 & 416,53 \\
\hline Subtotal A & 653,72 & 762,27 & 807,09 & 859,16 & 859,16 \\
\hline \multicolumn{6}{|l|}{ B. Operações manuais } \\
\hline Preparo da área & 29,30 & - & - & - & - \\
\hline Implantação & 325,81 & - & - & - & - \\
\hline Tratos culturais & 572,64 & $1.071,41$ & $1.052,30$ & $1.052,30$ & $1.052,30$ \\
\hline Colheita & - & 260,19 & 302,03 & 359,56 & 359,56 \\
\hline Subtotal B & 927,75 & $1.331,60$ & $1.354,33$ & $1.411,86$ & $1.411,86$ \\
\hline \multicolumn{6}{|l|}{ C. Insumos } \\
\hline Mudas & $3.181,50$ & - & - & - & - \\
\hline Corretivos e fertilizantes & 738,30 & $1.479,00$ & $1.686,30$ & $1.753,30$ & $1.686,30$ \\
\hline Defensivos & $1.577,21$ & $1.524,49$ & $1.524,49$ & $1.539,73$ & $1.539,73$ \\
\hline Sacos plásticos & - & 211,34 & 246,56 & 281,78 & 281,78 \\
\hline Subtotal C & $5.497,01$ & $3.214,83$ & $3.457,35$ & $3.574,81$ & $3.507,81$ \\
\hline Custo Op. Efetivo (COE) & $7.078,48$ & $5.308,70$ & $5.618,77$ & $5.845,83$ & $5.778,83$ \\
\hline Deprec. máq. e implementos & 163,43 & 190,57 & 201,77 & 214,79 & 214,79 \\
\hline Encargos sociais diretos & 306,16 & 439,43 & 446,93 & 465,91 & 465,91 \\
\hline Assistência técnica & 141,57 & 106,17 & 112,38 & 116,92 & 115,58 \\
\hline Encargos financeiros & 309,68 & 232,26 & 245,82 & 255,76 & 252,82 \\
\hline CESSR & 0 & 269,10 & 313,95 & 358,80 & 358,80 \\
\hline Subtotal D & 920,84 & $1.237,53$ & $1.320,85$ & $1.412,18$ & $1.407,90$ \\
\hline Custo Op. Total (COT) & $7.999,32$ & $6.546,23$ & $6.939,62$ & $7.258,01$ & $7.186,73$ \\
\hline Custo Total acumulado & $7.999,32$ & $14.545,55$ & $21.485,16$ & $28.743,17$ & $35.929,90$ \\
\hline Custo/kg produzido & - & 0,28 & 0,30 & 0,32 & 0,36 \\
\hline \multirow{2}{*}{ Especificações } & \multicolumn{5}{|c|}{ Manejo Nutricional 2 (MN2) } \\
\hline & Formação & $2^{\circ}$ ano & $3^{\circ}$ ano & $4^{\circ}$ ano & $5^{\circ}$ ano \\
\hline \multicolumn{6}{|l|}{ A. Operações mecanizadas } \\
\hline Preparo da área & 325,51 & - & - & - & - \\
\hline Implantação & 133,06 & - & - & - & - \\
\hline Tratos culturais & 195,15 & 436,85 & 442,63 & 442,63 & 442,63 \\
\hline Colheita & - & 379,65 & 416,53 & 488,13 & 542,37 \\
\hline Subtotal A & 653,72 & 816,50 & 859,16 & 930,76 & 985 \\
\hline \multicolumn{6}{|l|}{ B. Operações manuais } \\
\hline Preparo da área & 29,29 & - & - & - & - \\
\hline Implantação & 325,81 & - & - & - & - \\
\hline Tratos culturais & 572,64 & $1.071,41$ & $1.052,30$ & $1.052,30$ & $1.052,30$ \\
\hline Colheita & - & 303,56 & 345,17 & 404,50 & 449,45 \\
\hline Subtotal B & 927,74 & $1.374,97$ & $1.397,47$ & $1.456,80$ & $1.501,75$ \\
\hline \multicolumn{6}{|l|}{ C. Insumos } \\
\hline Mudas & $3.181,50$ & - & - & - & - \\
\hline Corretivos e fertilizantes & $1.030,60$ & $2.271,80$ & $2.271,80$ & $2.372,30$ & $2.271,80$ \\
\hline Defensivos & $1.577,21$ & $1.524,49$ & $1.524,49$ & $1.524,49$ & $1.539,70$ \\
\hline Sacos plásticos & - & 246,56 & 281,78 & 317,00 & 352,22 \\
\hline Subtotal C & $5.789,31$ & $4.042,85$ & $4.078,07$ & $4.213,79$ & $4.163,72$ \\
\hline Custo Op. Efetivo (COE) & $7.370,77$ & $6.234,32$ & $6.334,70$ & $6.601,35$ & $6.650,47$ \\
\hline Deprec. máq. e implementos & 163,43 & 190,57 & 201,77 & 214,79 & 214,79 \\
\hline Encargos sociais diretos & 306,16 & 439,43 & 446,93 & 465,91 & 465,91 \\
\hline Assistência técnica & 141,57 & 106,17 & 112,38 & 116,92 & 115,58 \\
\hline Encargos financeiros & 309,68 & 232,26 & 245,82 & 255,76 & 252,82 \\
\hline CESSR & 0 & 269,10 & 313,95 & 358,80 & 358,80 \\
\hline Subtotal D & 920,84 & $1.237,53$ & $1.320,85$ & $1.412,18$ & $1.407,90$ \\
\hline Custo Op. Total (COT) & $7.999,32$ & $6.546,23$ & $6.939,62$ & $7.258,01$ & $7.186,73$ \\
\hline Custo total acumulado & $7.999,32$ & $14.545,55$ & $21.485,16$ & $28.743,17$ & $35.929,90$ \\
\hline Custo/kg produzido & - & 0,28 & 0,30 & 0,32 & 0,36 \\
\hline
\end{tabular}

Fonte: Dados da pesquisa (2010). 
Tabela 3. Estimativa do custo de produção de bananeiras do subgrupo Cavendish, de acordo com o tipo de manejo nutricional (MN3 e MN4), em reais por hectare ( Região do Médio Paranapanema, SP, 2009/2010).

\begin{tabular}{|c|c|c|c|c|c|}
\hline \multirow{2}{*}{ Especificações } & \multicolumn{5}{|c|}{ Manejo Nutricional 3 (MN3) } \\
\hline & Formação & $2^{\circ}$ ano & $3^{\circ}$ ano & $4^{\circ}$ ano & $5^{\circ}$ ano \\
\hline \multicolumn{6}{|l|}{ A. Operações mecanizadas } \\
\hline Preparo da área & 325,51 & - & - & - & - \\
\hline Implantação & 133,06 & - & - & - & - \\
\hline Tratos culturais & 195,15 & 436,85 & 442,63 & 442,63 & 442,63 \\
\hline Colheita & - & 433,89 & 468,59 & 520,67 & 596,60 \\
\hline Subtotal A & 653,72 & 870,74 & 911,22 & 963,30 & $1.039,23$ \\
\hline \multicolumn{6}{|l|}{ B. Operações manuais } \\
\hline Preparo da área & 29,29 & - & - & - & - \\
\hline Implantação & 325,81 & - & - & - & - \\
\hline Tratos culturais & 572,64 & $1.071,41$ & $1.052,30$ & $1.052,30$ & $1.052,30$ \\
\hline Colheita & - & 346,93 & 388,32 & 431,47 & 431,47 \\
\hline Subtotal B & 927,74 & $1.418,34$ & $1.440,62$ & $1.483,77$ & $1.483,77$ \\
\hline \multicolumn{6}{|l|}{ C. Insumos } \\
\hline Mudas & $3.181,50$ & - & - & - & - \\
\hline Corretivos e fertilizantes & $1.419,60$ & $1.987,30$ & $1.987,30$ & $1.987,30$ & $1.987,30$ \\
\hline Defensivos & $1.577,21$ & $1.524,49$ & $1.524,49$ & $1.524,49$ & $1.524,49$ \\
\hline Sacos plásticos & - & 281,79 & 317,01 & 352,22 & 387,46 \\
\hline Subtotal C & $6.178,31$ & $3.793,58$ & $3.828,80$ & $3.864,01$ & $3.899,25$ \\
\hline Custo Op. Efetivo (COE) & $7.759,77$ & $6.082,66$ & $6.180,64$ & $6.311,08$ & $6.422,25$ \\
\hline Deprec. máq. e implementos & 163,43 & 217,69 & 227,81 & 240,83 & 259,81 \\
\hline Encargos sociais diretos & 306,15 & 468,05 & 475,40 & 489,64 & 489,64 \\
\hline Assistência técnica & 155,20 & 121,65 & 123,61 & 126,22 & 128,45 \\
\hline Encargos financeiros & 339,49 & 266,12 & 270,40 & 276,11 & 280,97 \\
\hline CESSR & - & 358,80 & 403,65 & 448,50 & 493,35 \\
\hline Subtotal D & 964,27 & $1.432,31$ & $1.500,88$ & $1.581,30$ & $1.652,22$ \\
\hline Custo Op. Total (COT) & $8.724,04$ & $7.514,97$ & $7.681,52$ & $7.892,38$ & $8.074,47$ \\
\hline Custo total acumulado & $8.724,04$ & $16.239,01$ & $23.920,52$ & $31.812,90$ & $39.887,37$ \\
\hline Custo/kg produzido & - & 0,24 & 0,26 & 0,28 & 0,29 \\
\hline \multirow{2}{*}{ Especificações } & \multicolumn{5}{|c|}{ Manejo Nutricional 4 (MN4) } \\
\hline & Formação & $2^{\circ}$ ano & $3^{\circ}$ ano & $4^{\circ}$ ano & $5^{\circ}$ ano \\
\hline \multicolumn{6}{|l|}{ A. Operações mecanizadas } \\
\hline Preparo da área & 325,51 & - & - & - & - \\
\hline Implantação & 133,06 & - & - & - & - \\
\hline Tratos culturais & 195,15 & 436,85 & 442,63 & 442,63 & 442,63 \\
\hline Colheita & - & 433,89 & 468,59 & 520,67 & 596,60 \\
\hline Subtotal A & 653,72 & 870,74 & 911,22 & 963,30 & $1.039,23$ \\
\hline \multicolumn{6}{|l|}{ B. Operações manuais } \\
\hline Preparo da área & 29,29 & - & - & - & - \\
\hline Implantação & 325,81 & - & - & - & - \\
\hline Tratos culturais & 572,64 & $1.071,41$ & $1.052,30$ & $1.052,30$ & $1.052,30$ \\
\hline Colheita & - & 346,93 & 388,32 & 431,47 & 494,39 \\
\hline Subtotal B & 927,74 & $1.418,34$ & $1.440,62$ & $1.483,77$ & $1.546,69$ \\
\hline \multicolumn{6}{|l|}{ C. Insumos } \\
\hline Mudas & $3.181,50$ & - & - & - & - \\
\hline Corretivos e fertilizantes & $1.419,60$ & $2.434,30$ & $2.434,30$ & $2.302,30$ & $2.434,30$ \\
\hline Defensivos & $1.577,21$ & $1.524,49$ & $1.524,49$ & $1.524,49$ & $1.524,49$ \\
\hline Sacos plásticos & - & 281,79 & 317,01 & 352,22 & 387,46 \\
\hline Subtotal C & $6.178,31$ & $4.240,58$ & $4.275,80$ & $4.179,01$ & $4.346,25$ \\
\hline Custo Op. Efetivo (COE) & $7.759,77$ & $6.529,66$ & $6.627,64$ & $6.626,08$ & $6.932,17$ \\
\hline Deprec. máq. e implementos & 163,43 & 217,69 & 227,81 & 240,83 & 259,81 \\
\hline Encargos sociais diretos & 306,15 & 468,05 & 475,40 & 489,64 & 510,41 \\
\hline Assistência técnica & 155,20 & 130,59 & 132,55 & 132,52 & 138,64 \\
\hline Encargos financeiros & 339,49 & 285,67 & 289,96 & 289,89 & 303,28 \\
\hline CESSR & - & 358,8 & 403,65 & 448,50 & 493,35 \\
\hline Subtotal D & 964,27 & $1.460,80$ & $1.529,37$ & $1.601,38$ & $1.705,49$ \\
\hline Custo Op. Total (COT) & $8.724,04$ & $7.990,46$ & $8.157,01$ & $8.227,46$ & $8.637,66$ \\
\hline Custo total acumulado & $8.724,04$ & $16.714,50$ & $24.871,51$ & $33.098,98$ & $41.736,64$ \\
\hline Custo/kg produzido & - & 0,25 & 0,27 & 0,29 & 0,31 \\
\hline
\end{tabular}

Fonte: Dados da pesquisa (2010). 
Tabela 4. Estimativa do custo de produção de bananeiras do subgrupo Cavendish, de acordo com o tipo de manejo nutricional (MN5), em reais por hectare (Região do Médio Paranapanema, SP, 2009/2010).

\begin{tabular}{|c|c|c|c|c|c|}
\hline \multirow{2}{*}{ Especificações } & \multicolumn{5}{|c|}{ Manejo Nutricional 5 (MN5) } \\
\hline & Formação & $2^{\circ}$ ano & $3^{\circ}$ ano & $4^{\circ}$ ano & $5^{\circ}$ ano \\
\hline \multicolumn{6}{|l|}{ A. Operações mecanizadas } \\
\hline Preparo da área & 325,51 & - & - & - & - \\
\hline Implantação & 133,06 & - & - & - & - \\
\hline Tratos culturais & 195,15 & 436,85 & 442,63 & 442,63 & 442,63 \\
\hline Colheita & - & 488,13 & 520,67 & 596,60 & 650,84 \\
\hline Subtotal A & 653,72 & 924,98 & 963,30 & $1.039,23$ & $1.093,47$ \\
\hline \multicolumn{6}{|l|}{ B. Operações manuais } \\
\hline Preparo da área & 29,29 & - & - & - & - \\
\hline Implantação & 325,81 & - & - & - & - \\
\hline Tratos culturais & 572,64 & $1.071,41$ & $1.052,30$ & $1.052,30$ & $1.052,30$ \\
\hline Colheita & - & 404,50 & 431,47 & 494,39 & 539,34 \\
\hline Subtotal B & 927,74 & $1.475,91$ & $1.483,77$ & $1.546,69$ & $1.591,64$ \\
\hline \multicolumn{6}{|l|}{ C. Insumos } \\
\hline Mudas & $3.181,50$ & - & - & - & - \\
\hline Corretivos e fertilizantes & $1.231,60$ & $3.775,00$ & $3.775,00$ & $3.775,00$ & $3.775,00$ \\
\hline Defensivos & $1.577,21$ & $1.524,49$ & $1.524,49$ & $1.524,49$ & $1.524,49$ \\
\hline Sacos plásticos & - & 317,01 & 352,22 & 387,46 & 422,68 \\
\hline Subtotal C & $5.990,31$ & $5.616,50$ & $5.651,71$ & $5.686,95$ & $5.722,17$ \\
\hline Custo Op. Efetivo (COE) & $7.571,77$ & $8.017,39$ & $8.098,78$ & $8.272,87$ & $8.407,28$ \\
\hline Deprec. máq. e implementos & 163,43 & 231,25 & 240,83 & 259,81 & 273,37 \\
\hline Encargos sociais diretos & 306,15 & 487,05 & 489,64 & 510,41 & 525,24 \\
\hline Assistência técnica & 151,44 & 160,35 & 161,98 & 165,46 & 168,15 \\
\hline Encargos financeiros & 331,26 & 350,76 & 354,32 & 361,94 & 367,82 \\
\hline CESSR & - & 403,65 & 448,50 & 493,35 & 538,20 \\
\hline Subtotal D & 952,28 & $1.633,05$ & $1.695,27$ & $1.790,96$ & $1.872,77$ \\
\hline Custo Op. Total (COT) & $8.524,05$ & $9.650,44$ & $9.794,05$ & $10.063,83$ & $10.280,05$ \\
\hline Custo total acumulado & $8.524,05$ & $18.174,50$ & $27.968,54$ & $38.032,38$ & $48.312,43$ \\
\hline Custo/kg produzido & - & 0,26 & 0,29 & 0,31 & 0,33 \\
\hline
\end{tabular}

Fonte: Dados da pesquisa (2010).

Tabela 5. Indicadores de rentabilidade da produção de bananeiras do subgrupo Cavendish, por hectare, de acordo com o tipo de manejo nutricional (MN1, MN2, MN3, MN4 e MN5) (Região do Médio Paranapanema, SP, 2009/2010).

\begin{tabular}{|c|c|c|c|c|c|c|}
\hline Item & Unidade & $2^{\circ}$ ano & $3^{\circ}$ ano & $4^{\circ}$ ano & $5^{\circ}$ ano & Total \\
\hline Receita Bruta & $\mathrm{R} \$ \mathrm{ha}^{-1}$ & & & & & \\
\hline MN1 & & $11.700,0$ & $13.650,0$ & $15.600,0$ & $15.600,0$ & $56.550,0$ \\
\hline MN2 & & $13.650,0$ & $15.600,0$ & $17.550,0$ & $19.500,0$ & $66.300,0$ \\
\hline MN3 & & $15.600,0$ & $17.550,0$ & $19.500,0$ & $21.450,0$ & $74.100,0$ \\
\hline MN4 & & $15.600,0$ & $17.550,0$ & $19.500,0$ & $21.450,0$ & $74.100,0$ \\
\hline MN5 & & $17.550,0$ & $19.500,0$ & $21.450,0$ & $23.400,0$ & $81.900,0$ \\
\hline Receita Líquida & $\mathrm{R} \$ \mathrm{ha}^{-1}$ & & & & & \\
\hline MN1 & & $3.153,9$ & $3.074,0$ & $2.970,7$ & $1.227,5$ & $10.426,1$ \\
\hline MN2 & & $3.968,9$ & $3.848,2$ & $3.488,9$ & $3.278,6$ & $14.584,6$ \\
\hline $\mathrm{MN} 3$ & & $5.904,0$ & $5.808,7$ & $5.627,5$ & $5.422,3$ & $22.762,5$ \\
\hline MN4 & & $5.428,5$ & $5.214,4$ & $5.054,7$ & $4.537,6$ & $20.235,2$ \\
\hline MN5 & & $5.768,5$ & $5.162,3$ & $4.394,0$ & $3.611,8$ & $18.936,6$ \\
\hline Índice de Lucratividade & $\%$ & & & & & Média \\
\hline MN1 & & 26,7 & 22,5 & 19,0 & 7,8 & 19,0 \\
\hline MN2 & & 29,1 & 24,7 & 19,9 & 16,8 & 22,6 \\
\hline MN3 & & 37,8 & 33,1 & 28,9 & 25,3 & 31,3 \\
\hline MN4 & & 34,8 & 29,7 & 25,9 & 21,1 & 27,9 \\
\hline MN5 & & 32,9 & 26,5 & 20,5 & 15,4 & 23,8 \\
\hline
\end{tabular}

Obs: Preço esperado de venda: R \$ 8,6 a caixa de $22 \mathrm{~kg}$. No ano de plantio/formação, os valores foram considerados iguais a 0 (zero).

Fonte: Elaborada a partir dos dados da tabela 1. 
O índice médio de lucratividade, nos cinco manejos, correspondeu a $24,9 \%$. O manejo menos rentável foi o MN1 (média de 19,0\%) e o mais lucrativo o MN3 (média de 31,3\%).

Em lavouras de banana 'Nanicão Jangada', em 2008, com preço de venda de $\mathrm{R} \$ 4,84 \mathrm{cx}$. $22 \mathrm{~kg}^{-1}$, a receita bruta foi de R $\$ 9.000,00 \mathrm{ha}^{-1}$, no segundo ano; $\mathrm{R} \$ 10.000,00 \mathrm{ha}^{-1}$, no terceiro; e R \$ 11.000,00 ha-1, nos anos subsequentes, sendo o investimento inicial recuperado ao término do terceiro ano. A partir do quarto ano, o índice de lucratividade chegou a $45,0 \%$ e o ponto de nivelamento próximo a $27 \mathrm{t} \mathrm{ha}^{-1}$, evidenciando ganhos expressivos ao produtor, posto que a produtividade média equivale a $40 \mathrm{t} \mathrm{ha}^{-1}$. Por sua vez, na cultura de banana cultivar 'Maçã', com produtividades de 14-17 t ha-1 , nos dois únicos anos produtivos, com preço de venda de $\mathrm{R} \$ 12,00 \mathrm{cx}$. $22 \mathrm{~kg}^{-1}$, a lucratividade média foi de $38,0 \%$. Ressalta-se que, apesar de a longevidade média desta cultura dificilmente ultrapassar três anos e de a lucratividade média ser menor que a da cultivar 'Nanicão Jangada', o retorno do investimento é mais rápido (Martins \& Furlaneto 2008).

\section{CONCLUSÃO}

Atualmente, o MN3 é o manejo nutricional recomendado, economicamente, para o cultivo de bananeiras do subgrupo Cavendish, na região do Médio Paranapanema, visto que proporciona índice médio de lucratividade $25,6 \%$ superior aos demais tratamentos, além de a receita líquida total ser, em média, 29,5\% superior aos outros tipos de manejo.

\section{REFERÊNCIAS}

ANUÁRIO DA AGRICULTURA BRASILEIRA (Agrianual). Banana. São Paulo: Instituto FNP, 2010. p. 192-204.

BORGES, A. L.; OLIVEIRA, A. M. G. Banana: nutrição, calagem e adubação. In: CORDEIRO, Z. J. M. Frutas do Brasil. Brasília, DF: Embrapa, 2000. p. 47-59.

FERNANDES, L. A. et al. Fertilidade do solo, nutrição mineral e produtividade da bananeira irrigada por dez anos. Pesquisa Agropecuária Brasileira, Brasília, DF, v. 43, n. 11, p. 1575-1581, 2008.

FURLANETO, F. P. B. et al. Análise econômica de sistemas de produção de banana (Musa sp.), cv. Grande Naine, na região do Médio Paranapanema, Estado de São Paulo. Cientifica, Jaboticabal, v. 35, n. 2, p. 188-195, 2007.
FURLANETO, F. P. B. et al. Custo de produção e rentabilidade da cultura da banana "maçã" (Musa spp.) na região do Médio Paranapanema, Estado de São Paulo, 2005. Informações Econômicas, São Paulo, v. 35, n. 12, p. 19-25, 2005.

KOGLER, E. V. et al. Estudo da viabilidade econômica do cultivo da banana irrigado por microaspersão em Bom Jesus da Lapa. Brasília, DF: UPIS, 2006.

LEITE, J. B. V. Banana. Ilhéus: Ceplac, 2001.

MARTIN, N. B. et al. Sistema integrado de custos agropecuários: CUSTAGRI. Informações Econômicas, São Paulo, v. 28, n. 1, p. 7-28, 1998.

MARTINS, A. N. Irrigação bem manejada diminui a água virtual na banana. São Paulo: Instituto FNP, 2010.

MARTINS, A. N.; FURLANETO, F. P. B. Bananicultura: pesquisas voltadas para a agricultura familiar. Revista Tecnologia \& Inovação Agropecuária, Campinas, v. 1, n. 2, p. 76-86, 2008.

MATSUNAGA, M. et al. Metodologia de custo de produção utilizada pelo Instituto de Economia Agrícola. Agricultura em São Paulo, São Paulo, v. 23, n. 1, p. 123-139, 1976.

MOREIRA, A.; FAGERIA, N. K. Repartição e remobilização de nutrientes na bananeira. Revista Brasileira de Fruticultura, Jaboticabal, v. 31, n. 2, p. 574-581, 2009.

NAVA, C.; ILLARREAL, E. Nitrogen, potasium, boron, magnesiun and zinc application to plantain plantations, Musa AAB cv. Horn with black Sigatoka incidence. Revista de la Facultad de Agronomia, Venezuela, v. 17, n. 1, p. 20-35, 2000.

OLIVEIRA, S. J. M.; ROCHA, V. G. Custo de produção da banana em Buritis, Rondônia, 2007. Porto Velho: Embrapa, 2007. (Comunicado técnico, 322).

PRADO, H. et al. Levantamento pedológico do pólo regional de desenvolvimento tecnológico dos agronegócios do Médio Paranapanema, Assis, SP. Campinas: Instituto Agronômico, 2003. (Boletim científico, 7).

SANTOS, S. C. et al. Adubação nitrogenada e potássica em três cultivares de bananeira. In: CONGRESSO BRASILEIRO DE FRUTICULTURA, 20., 2008, Vitória. Anais... Vitória: SBF, 2008. p. 263-276.

SANTOS, V. P. et al. Fertirrigação da bananeira cv. prataanã com N e K em um Argissolo Vermelho-Amarelo. Revista Brasileira de Fruticultura, Jaboticabal, v. 31, n. 2, p. 567-573, 2009.

SILVA NETO, S. P.; GUIMARÃES, T. G. Evolução da cultura da banana no Brasil e no mundo. Planaltina, DF: Embrapa Cerrados, 2011.

SOARES, F. A. L. et al. Acúmulo, exportação e restituição de nutrientes pelas bananeiras "Prata Anã" e "Grand Naine". Ciência Rural, Santa Maria, v. 38, n. 7, p. 20542058, 2008

TEIXEIRA, L. A. J. et al. Avaliação do estado nutricional de bananeiras do subgrupo Cavendish no Estado de São Paulo: normas DRIS e níveis críticos de nutrientes. Revista Brasileira de Fruticultura, Jaboticabal, v. 29, n. 3, p. 613620, 2007. 